\title{
Does quality of life among breast cancer survivors one year after diagnosis differ depending on urban and non-urban residence? A comparative study
}

\author{
Tracey DiSipio ${ }^{1 *}$, Sandi C Hayes ${ }^{1}$, Beth Newman ${ }^{1}$, Joanne Aitken ${ }^{2}$, Monika Janda ${ }^{1}$
}

\begin{abstract}
Background: This study examined the quality of life (QOL), measured by the Functional Assessment of Cancer Therapy (FACT) questionnaire, among urban $(n=277)$ and non-urban $(n=323)$ breast cancer survivors and women from the general population $(n=1140)$ in Queensland, Australia.

Methods: Population-based samples of breast cancer survivors aged $<75$ years who were 12 months postdiagnosis and similarly-aged women from the general population were recruited between 2002 and 2007.

Results: Age-adjusted QOL among urban and non-urban breast cancer survivors was similar, although QOL related to breast cancer concerns was the weakest domain and was lower among non-urban survivors than their urban counterparts (36.8 versus 40.4, $P<0.01$ ). Irrespective of residence, breast cancer survivors, on average, reported comparable scores on most QOL scales as their general population peers, although physical well-being was significantly lower among non-urban survivors (versus the general population, $P<0.01$ ). Overall, around 20\%-33\% of survivors experienced lower QOL than peers without the disease. The odds of reporting $\mathrm{QOL}$ below normative levels were increased more than two-fold for those who experienced complications following surgery, reported upper-body problems, had higher perceived stress levels and/or a poor perception of handling stress $(P<0.01$ for all).

Conclusions: Results can be used to identify subgroups of women at risk of low QOL and to inform components of tailored recovery interventions to optimize QOL for these women following cancer treatment.
\end{abstract}

\section{Background}

Breast cancer is a major public health concern, with one in eight women developing the disease before the age of 85 years in developed countries of the world $[1,2]$. Despite therapeutic advances, which have contributed to improvements in survival (five-year survival currently 87\%) [3] women continue to experience considerable physical and psychosocial dysfunction during and following treatment. While these quality of life (QOL) concerns are short-lived for some, others may struggle to regain expected levels of QOL longer term.

\footnotetext{
* Correspondence: t.disipio@qut.edu.au

${ }^{1}$ School of Public Health, Institute of Health and Biomedical Innovation, Queensland University of Technology, Victoria Park Road, Kelvin Grove, Queensland, 4059, Australia
}

QOL has been associated with adherence to treatment [4] and prognosis [5,6] and is now recognized as an important research outcome. International research on factors that influence QOL among breast cancer survivors has been extensive (over 300 published studies in 2008 alone integrated QOL as an outcome). Socio-demographic (e.g., income), general health (e.g., medical conditions) and treatment (e.g., adjuvant therapy) characteristics each have been associated with QOL [7], with the strength and consistency of the associations dependent on the characteristic of interest. Nevertheless, there remain subgroups of women for whom limited information on QOL is available, including those women who reside outside major metropolitan areas. This is important because approximately 
one-third of new breast cancer cases live outside major metropolitan areas [2].

In Australia, geographic residence influences stage at diagnosis and type of surgery, with those living in rural areas more likely to have a mastectomy than their urban counterparts (38\% versus $25 \%$, respectively) [8-10]. Geographic residence also influences access to health services [11], as fewer than half of regional/rural hospitals administer chemotherapy [12], and fewer still provide radiotherapy services [13]. Further, rural Australian women often have to travel in excess of 100 kilometers (i.e., 62 miles) to receive adjuvant treatment and are away from home for approximately 20 to 43 days for chemotherapy and radiotherapy treatment, respectively $[14,15]$. Hence, it seems plausible that rural women with breast cancer may have unique and additional burdens, such as disruption to family life, work and financial security $[14,16]$, which ultimately may influence QOL differently to that observed for women residing in urban areas.

Research that compares QOL between urban and nonurban cancer survivors is lacking, and from those studies that exist, results are inconsistent. Two studies suggest that rural breast cancer survivors fare worse $[17,18]$, while one indicates that QOL is superior among a rural group of mixed cancer survivors [19], when compared with their urban counterparts. Further, there is a paucity of information comparing the QOL among cancer groups with that of the general population, making interpretation of findings challenging. Therefore, this paper examines whether QOL differs between urban and non-urban women 12 months following breast cancer diagnosis and compares their QOL with women from the general population residing in their respective geographic areas. We also sought to identify characteristics of breast cancer survivors associated with reporting QOL below normative levels.

\section{Methods}

\section{Breast cancer study samples}

The Pulling Through Study (PTS) was a longitudinal, population-based study among breast cancer survivors living within 100 kilometers (i.e., 62 miles) of the capital city of Brisbane in Queensland, Australia, and diagnosed in 2002 [20,21]. This study was extended to include survivors from non-urban areas of Queensland, diagnosed between April 2006 and March 2007 [22]. The Accessibility/Remoteness Index of Australia (ARIA+) classification system was used to define place of residence as either major city, inner regional, outer regional, remote or very remote, and is based on road distance and population size of the nearest town [23]. The selected localities within the perimeter of Brisbane fall within the ARIA+ classification for major cities and hereafter are referred to as 'urban'. Residents of inner regional, remote and very remote areas were pooled as the 'nonurban' group and reflect the reduced access to a range of oncology services experienced by those who live outside state capital cities, irrespective of the level of remoteness [12].

Eligible women, diagnosed with unilateral breast cancer at age 74 years or younger, were randomly selected through the Queensland Cancer Registry (target sample). All cancer diagnoses in Queensland are required to be reported to the Registry and therefore these records provide an accurate sampling frame for recruitment. Since breast cancer is mostly a disease of women $50 \mathrm{yrs}$ or older and to ensure adequate numbers were available for specific age group analyses, younger women were over-sampled in the urban arm of the study, while $100 \%$ of eligible non-urban women were recruited for all age groups. Following appropriate ethical approval and the requirements of the cancer registry, doctor consent to contact eligible women (provided for $82 \%$ of the urban sample and $90 \%$ of the non-urban sample) and participant consent was sought. Overall, 277 urban and 323 non-urban women returned completed quuestionnaires at 12 months post-diagnosis $(66 \%$ and $71 \%$ of eligible women with doctor consent for the urban and nonurban arms, respectively).

\section{General population study sample}

Following ethical approval, the general Queensland population sample was derived from the Queensland Cancer Risk Study (QCRS), a population-based survey conducted in 2004 among English-speaking residents of Queensland, aged 20-75 years, randomly sampled within strata defined by gender, age and geographic region (defined by the ARIA+ classification as as major city, inner regional, outer regional or remote/very remote). Further details about the study methods are described elsewhere [24]. Briefly, of the 8,398 adults who agreed to participate in the self-administered questionnaire, $5822(69.3 \%)$ returned surveys, of which 2727 contained QOL information. Analyses reported in this paper include women for whom QOL data were available and who had no prior history of breast cancer, with 675 living in urban and 465 in non-urban areas of Queensland, as defined by the ARIA+.

\section{Questionnaires}

QOL was measured among women with breast cancer at 12 months post-diagnosis using the Functional Assessment of Cancer Therapy (FACT-G) questionnaire, which is comprised of 27 items rated on a five-point Likert scale (ranging from $0=$ 'not at all' to $4=$ 'very much') and includes four subscales (physical, social, emotional, and functional well-being). Higher scores represent better well-being. Women in the QCRS received the general population $\mathrm{FACT}$ instrument 
(FACT-GP), which is identical to the FACT-G except it excludes six illness-related items inappropriate for the general population $[25,26]$. Overall FACT-GP summary scores and subscales were pro-rated as per the FACT manual to obtain scores comparable to the FACT-G [27], resulting in total scores for all study groups ranging from 0-108 for overall QOL, 0-28 for the physical, social, and functional well-being subscales, and 0-24 for the emotional well-being subscale. Women with breast cancer also completed 13 questions on breast cancer concerns and arm morbidity $(\mathrm{FACT}-\mathrm{B}+4)$, with total scores from 0-52 for the breast cancer concerns subscale, and 0-160 for overall FACT-B+4. The FACT instrument has excellent reliability and validity [28].

Demographic (age, marital status, educational level, private health insurance, occupation $[29,30]$ and income), general health (smoking status, body mass index, co-morbidities, complications following surgery, upper-body function [31], physical activity and stress levels including perceived handling of stress) and treatment (chemotherapy, radiotherapy, hormone therapy) characteristics for the breast cancer study participants were also obtained via the questionnaire, whereas information on tumor characteristics were abstracted from histopathology reports (e.g., type of surgery, maximum tumor size and grade, and lymph node status).

\section{Statistical analysis}

Distributions of the FACT scores were approximately normal and hence were summarized as means with 95\% confidence intervals (CIs) using SPSS (SPSS Inc, Chicago, IL, version 14). Analysis of variance tests compared age-adjusted mean QOL scores at 12 months post-diagnosis between urban and non-urban breast cancer survivors. Comparisons between breast cancer survivors and women from the general population involved general linear regression models to obtain QOL scores adjusted for characteristics that differed between the groups (i.e., potential confounding factors).

Descriptive results presented in this study have been adjusted for the sampling fraction used to identify younger breast cancer patients from urban areas (weighting applied: $<50$ years:1.0; $\geq 50$ years:1.3). The general population comparison group was also weighted by age, based on Australian Bureau of Statistics data, so that results reflect the actual female Queensland resident population (weighting applied for urban, regional, outer regional, remote and very remote: $<50$ years: 1.3 , $1.3,1.4,1.5$ and 0.9 , respectively; $\geq 50$ years:0.8, $0.8,0.7$, 0.6 and 1.1 , respectively) [33]. The conventional $P<$ 0.05 level (two-tailed) was accepted as statistically significant. Differences of eight or more points in mean FACT-B+4 scores, five or more points in mean FACT-G scores, three or more points on the breast cancer concerns subscale and two or more points for all other subscales between urban and non-urban breast cancer survivors or between women with breast cancer and their general population peers were considered clinically important, as recommended by developers of the FACT [25]. For correlates, a difference in odds ratios (ORs) of $\geq 1.8$ or $\leq 0.6$ was considered to be of potential clinical relevance.

As suggested by Fayers [34], a new outcome measure was calculated to characterize breast cancer survivors whose QOL was below normative levels. QOL values were calculated for each five-year age stratum of the general population study group and subtracted from the QOL score within the same age group of women with breast cancer (i.e., case FACT-G minus general population comparison group FACT-G) separately by urban and non-urban residence [34]. Positive scores indicate higher QOL, and negative scores indicate lower QOL, among cases relative to age- (within five years) and residence-matched peers. Relative overall QOL (FACT-G) was then categorized into groups using score differentials considered clinically important to investigate the proportions of breast cancer survivors with relative overall QOL lower than ( -5.0 points or more), similar to $(>-5.0$ to $<+5.0)$ or better than $(+5.0$ points or more $)$ the general population study group. Relative QOL was also calculated for each subscale, using two points as the critical threshold. A dichotomous outcome variable was defined, combining the 'similar' and 'better' groups, and binary logistic regression was used to generate ORs and $95 \%$ CIs to identify demographic, general health, and clinical characteristics associated with QOL status below the norm compared to the 'similar/better' group. A range of potentially important correlates were explored, however, only those that were found to be statistically significant or clinically important are reported. Formal tests of interactions between residence and each of the characteristics of interest did not yield any statistically significant results, therefore pooled results, adjusted for residence, are presented.

\section{Results}

\section{Sample characteristics}

Demographic and disease characteristics were similar for the women with breast cancer in this study and those in the target sample. The majority of women (75-80\%) were diagnosed with infiltrating ductal carcinoma, approximately $60 \%$ received complete local excision of their tumour and more than $50 \%$ had 10 or more lymph nodes removed. However, participants among urban breast cancer survivors had somewhat smaller tumor size (median tumour size was $14 \mathrm{~mm}$ ) when compared with the target sample [20-22]. For the majority of demographic and general health characteristics, women with breast cancer had similar characteristics, 
Table 1 Participant Characteristics

\begin{tabular}{|c|c|c|c|c|c|c|c|c|}
\hline \multirow[t]{2}{*}{ Characteristics } & \multicolumn{2}{|c|}{$\begin{array}{c}\text { Urban general } \\
\text { population }^{\mathrm{a}}(\mathrm{n}=675)\end{array}$} & \multicolumn{2}{|c|}{$\begin{array}{l}\text { Urban breast cancer } \\
\text { survivors }^{\mathrm{b}}(\mathrm{n}=277)\end{array}$} & \multicolumn{2}{|c|}{$\begin{array}{c}\text { Non-urban general } \\
\text { population }^{\mathrm{a}}(\mathrm{n}=465)\end{array}$} & \multicolumn{2}{|c|}{$\begin{array}{l}\text { Non-urban breast cancer } \\
\text { survivors }(n=323)\end{array}$} \\
\hline & $n$ & $\%$ & $n$ & $\%$ & $n$ & $\%$ & $\mathrm{n}$ & $\%$ \\
\hline \multicolumn{9}{|l|}{ Demographic characteristics } \\
\hline Age (years) & & & & * & & & & \\
\hline$<50$ & 298 & 57.0 & 99 & 30.0 & 185 & 55.6 & 107 & 33.1 \\
\hline $50+$ & 377 & 43.0 & 178 & 70.0 & 280 & 44.4 & 216 & 66.9 \\
\hline Marital status & & & & * & & & & $\dagger$ \\
\hline Married, or living as married & 520 & 77.6 & 186 & 66.6 & 361 & 80.1 & 248 & 76.8 \\
\hline Not married & 155 & 22.4 & 91 & 33.4 & 104 & 19.9 & 75 & 23.2 \\
\hline Education level & & & & * & & & & * \\
\hline Grade 10 or below & 219 & 30.2 & 125 & 46.5 & 186 & 37.0 & 173 & 53.6 \\
\hline Grade $12 /$ rade/TAFE & 278 & 42.5 & 95 & 33.7 & 183 & 40.7 & 102 & 31.6 \\
\hline University or college degree & 178 & 27.3 & 57 & 19.9 & 96 & 22.3 & 48 & 14.9 \\
\hline Private health insurance status & & & & * & & & & $\dagger$ \\
\hline Yes & 398 & 58.0 & 200 & 72.4 & 222 & 48.5 & 140 & 43.3 \\
\hline No & 277 & 42.0 & 77 & 27.6 & 243 & 51.5 & 183 & 56.7 \\
\hline \multicolumn{9}{|l|}{ General health characteristics } \\
\hline \multicolumn{9}{|l|}{ Smoking status } \\
\hline Never smoked & 364 & 53.6 & 163 & 59.3 & 250 & 52.9 & 184 & 57.0 \\
\hline Past smoker & 216 & 31.2 & 84 & 30.0 & 149 & 31.7 & 102 & 31.6 \\
\hline Current smoker & 95 & 15.2 & 30 & 10.7 & 66 & 15.3 & 37 & 11.5 \\
\hline \multicolumn{9}{|l|}{ Physical activity ${ }^{c}$} \\
\hline Sedentary & 94 & 17.5 & 34 & 12.6 & 81 & 13.7 & 68 & 21.1 \\
\hline Insufficient activity & 194 & 27.9 & 67 & 23.9 & 125 & 29.4 & 55 & 17.0 \\
\hline Sufficient activity & 387 & 54.6 & 176 & 63.5 & 259 & 57.0 & 200 & 61.9 \\
\hline Body mass index $\left(\mathrm{kg} / \mathrm{m}^{2}\right)$ & & & & * & & & & $\dagger$ \\
\hline $\begin{array}{l}\text { Underweight/Normal (up to } \\
\text { 24.9) }\end{array}$ & 335 & 41.5 & 108 & 38.5 & 183 & 50.7 & 116 & 35.9 \\
\hline Overweight (25-29.9) & 203 & 27.4 & 80 & 29.0 & 134 & 29.6 & 91 & 28.2 \\
\hline Obese $(30+)$ & 106 & 25.1 & 55 & 20.0 & 119 & 14.9 & 100 & 31.0 \\
\hline Missing & 31 & 6.0 & 34 & 12.5 & 29 & 4.7 & 16 & 5.0 \\
\hline Number of co-morbidities ${ }^{d}$ & & & & $*$ & & & & $*^{\dagger}$ \\
\hline None & 126 & 21.6 & 68 & 23.8 & 84 & 21.4 & 55 & 17.0 \\
\hline One & 158 & 19.0 & 68 & 23.7 & 79 & 24.7 & 74 & 22.9 \\
\hline Two & 133 & 19.7 & 69 & 25.6 & 95 & 19.2 & 79 & 24.5 \\
\hline Three or more & 258 & 39.6 & 72 & 27.0 & 206 & 34.7 & 115 & 35.6 \\
\hline \multicolumn{9}{|l|}{ Clinical characteristics } \\
\hline Adjuvant treatment & - & - & & & - & - & & $\dagger$ \\
\hline None & & & 42 & 15.8 & & & 59 & 18.3 \\
\hline Chemotherapy only & & & 34 & 11.3 & & & 33 & 10.2 \\
\hline Radiotherapy only & & & 119 & 43.8 & & & 105 & 32.5 \\
\hline Both & & & 82 & 29.1 & & & 126 & 39.0 \\
\hline Number of complications ${ }^{\mathrm{e}}$ & - & - & & & - & - & & $\dagger$ \\
\hline None & & & 54 & 19.7 & & & 133 & 41.2 \\
\hline Yes, one to four & & & 223 & 80.3 & & & 190 & 58.8 \\
\hline
\end{tabular}

Abbreviations:

* Statistically significant difference $(P<0.05)$ between the general population and breast cancer survivors by place of location.

† Statistically significant difference $(P<0.05)$ between urban and non-urban breast cancer survivors.

Notes:

(a) Column percentages are standardized to the 2003 Queensland population by age.

(b) Column percentages have been weighted to correct for sampling.

(c) 'Sedentary' is defined as no activity; 'Insufficient' time is defined as participating in some activity but less than 150 minutes per week, using the sum of walking, moderate activity and vigorous activity (weighted by 2); 'Sufficient' time is defined as 150 minutes per week, using the sum of walking, moderate activity and vigorous activity (weighted by 2) [45]

(d) Co-morbidities include heart conditions, high blood pressure, high cholesterol, stroke, diabetes, lung conditions, stomach or duodenal ulcer, migraine or headaches, arthritis, cancer other than breast, depression and other prolonged or serious illness.

(e) Complications include wound infection, other infection, skin reaction, seroma. 
Table 2 QOL scores at 12 months post-diagnosis for urban and non-urban breast cancer survivors

\begin{tabular}{|c|c|c|c|c|c|c|}
\hline \multirow[t]{2}{*}{ Quality of life } & \multicolumn{2}{|c|}{$\begin{array}{c}\text { Urban breast cancer survivors ( } \mathrm{n} \\
=277 \text { ) }\end{array}$} & \multicolumn{2}{|c|}{$\begin{array}{l}\text { Non-urban breast cancer } \\
\text { survivors }(n=323)\end{array}$} & \multicolumn{2}{|c|}{$\begin{array}{c}\text { Differences between residence } \\
\text { groups }\end{array}$} \\
\hline & Mean $^{a}$ & $95 \% \mathrm{Cl}$ & Mean $^{\mathrm{a}}$ & $95 \% \mathrm{Cl}$ & $P$-Value & clinical $^{\text {b }}$ \\
\hline Physical well-being (0-28) & 24.7 & $24.1,25.2$ & 22.8 & $22.3,23.3$ & $<0.01$ & $x$ \\
\hline Social well-being (0-28) & 22.7 & $22.0,23.4$ & 22.5 & $21.8,23.1$ & 0.67 & $x$ \\
\hline Emotional well-being (0-24) & 20.1 & $19.6,20.5$ & 19.2 & $18.7,19.6$ & $<0.01$ & $x$ \\
\hline Functional well-being (0-28) & 22.4 & $21.8,23.1$ & 21.7 & $21.1,22.3$ & 0.09 & $x$ \\
\hline Breast cancer concerns (0-52) & 40.4 & $39.5,41.4$ & 36.8 & $36.0,37.7$ & $<0.01$ & $\checkmark$ \\
\hline FACT-G (0-108) & 89.7 & $87.9,91.5$ & 86.3 & $84.7,88.0$ & $<0.01$ & $x$ \\
\hline FACT-B+4 (0-160) & 130.2 & $127.7,132.7$ & 122.6 & $120.3,125.0$ & $<0.01$ & $x$ \\
\hline
\end{tabular}

Abbreviations:

FACT-G: Functional Assessment of Cancer Therapy-General; FACTB+4: Functional Assessment of Cancer Therapy-Breast additional four questions.

Notes:

(a) Adjusted for age.

(b) $x$ : clinically meaningful difference between groups (two+ points for physical, social, emotional and functional well-being, three+ points for breast cancer concerns, five+ points for FACT-G, eight+ points for FACT-B+4); $\checkmark$ : no clinically meaningful difference between groups.

irrespective of place of residence. However, the urban compared to the non-urban breast cancer sample was more likely to be unmarried, have private health insurance and report fewer co-morbidities, and less likely to be obese (Table 1). Non-urban compared to urban women with breast cancer were more likely to have multiple forms of adjuvant therapy and less likely to report multiple complications.

A comparison of women with or without breast cancer showed significant differences for several demographic and general health characteristics (Table 1). Breast cancer survivors tended to be older or have lower educational levels when compared with the general population, irrespective of residence. In addition, urban breast cancer survivors were more likely to be single, have private health insurance, and/or fewer co-morbidities (other than breast cancer), while non-urban breast cancer survivors were more likely to be sedentary and/ or have two or more co-morbidities (other than breast cancer), when compared with their general population counterparts. While there was a significant $(P<0.05)$ difference in body mass index between urban breast cancer survivors and their general population peers, this was attenuated when missing values were omitted from analyses.

QOL among urban and non-urban breast cancer survivors Although urban breast cancer survivors reported higher age-adjusted QOL summary and subscale scores than

Table 3 Adjusted mean QOL for women with breast cancer compared with the general population stratified by residence location

\begin{tabular}{|c|c|c|c|c|c|c|c|}
\hline \multirow[t]{2}{*}{ Quality of life } & \multirow[t]{2}{*}{ Residence } & \multicolumn{2}{|c|}{ General population } & \multicolumn{2}{|c|}{ Breast cancer survivors } & \multicolumn{2}{|c|}{ Difference between groups } \\
\hline & & Mean $^{\mathrm{a}}$ & $95 \% \mathrm{Cl}$ & Mean $^{a}$ & $95 \% \mathrm{Cl}$ & $P$-Value & clinical $^{\mathrm{b}}$ \\
\hline \multirow[t]{2}{*}{ Physical well-being (0-28) } & urban & 25.0 & $24.8,25.3$ & 24.2 & $23.8,24.6$ & $<0.01$ & $x$ \\
\hline & non-urban & 25.1 & $24.7,25.5$ & 22.7 & $22.2,23.2$ & $<0.01$ & $\checkmark$ \\
\hline \multirow[t]{2}{*}{ Social well-being (0-28) } & urban & 19.9 & $19.5,20.4$ & 22.4 & $21.6,23.2$ & $<0.01$ & $\checkmark$ \\
\hline & non-urban & 19.6 & $19.0,20.2$ & 22.4 & $21.7,23.1$ & $<0.01$ & $\checkmark$ \\
\hline \multirow[t]{2}{*}{ Emotional well-being (0-24) } & urban & 21.1 & $20.8,21.4$ & 19.6 & $19.1,20.0$ & $<0.01$ & $x$ \\
\hline & non-urban & 20.9 & $20.5,21.2$ & 19.2 & $18.8,19.7$ & $<0.01$ & $x$ \\
\hline \multirow[t]{2}{*}{ Functional well-being (0-28) } & urban & 20.6 & $20.2,21.1$ & 22.0 & $21.3,22.7$ & $<0.01$ & $x$ \\
\hline & non-urban & 20.2 & $19.7,20.8$ & 21.6 & $21.0,22.3$ & $<0.01$ & $x$ \\
\hline \multirow[t]{2}{*}{ FACT-G (0-108) } & urban & 86.9 & $85.8,88.0$ & 88.0 & $86.3,89.8$ & 0.28 & $x$ \\
\hline & non-urban & 85.8 & $84.4,87.3$ & 86.2 & $84.4,87.9$ & 0.79 & $x$ \\
\hline
\end{tabular}

Abbreviations:

FACT-G: Functional Assessment of Cancer Therapy-General.

Notes:

(a) Adjusted for age (years), marital status (married or living as married, not married), education level (low, moderate, high), private health insurance status (yes, no), smoking status (never smoked, past smoker, current smoker), physical activity (sedentary, insufficient, sufficient), body mass index (underweight/healthy, overweight, obese, missing), and co-morbidities (none, one, two, three or more).

(b) $x$ : clinically meaningful difference between groups (two+ points for physical, social, emotional and functional well-being, five+ points for FACT-G); $\checkmark$ : no clinically meaningful difference between groups. 


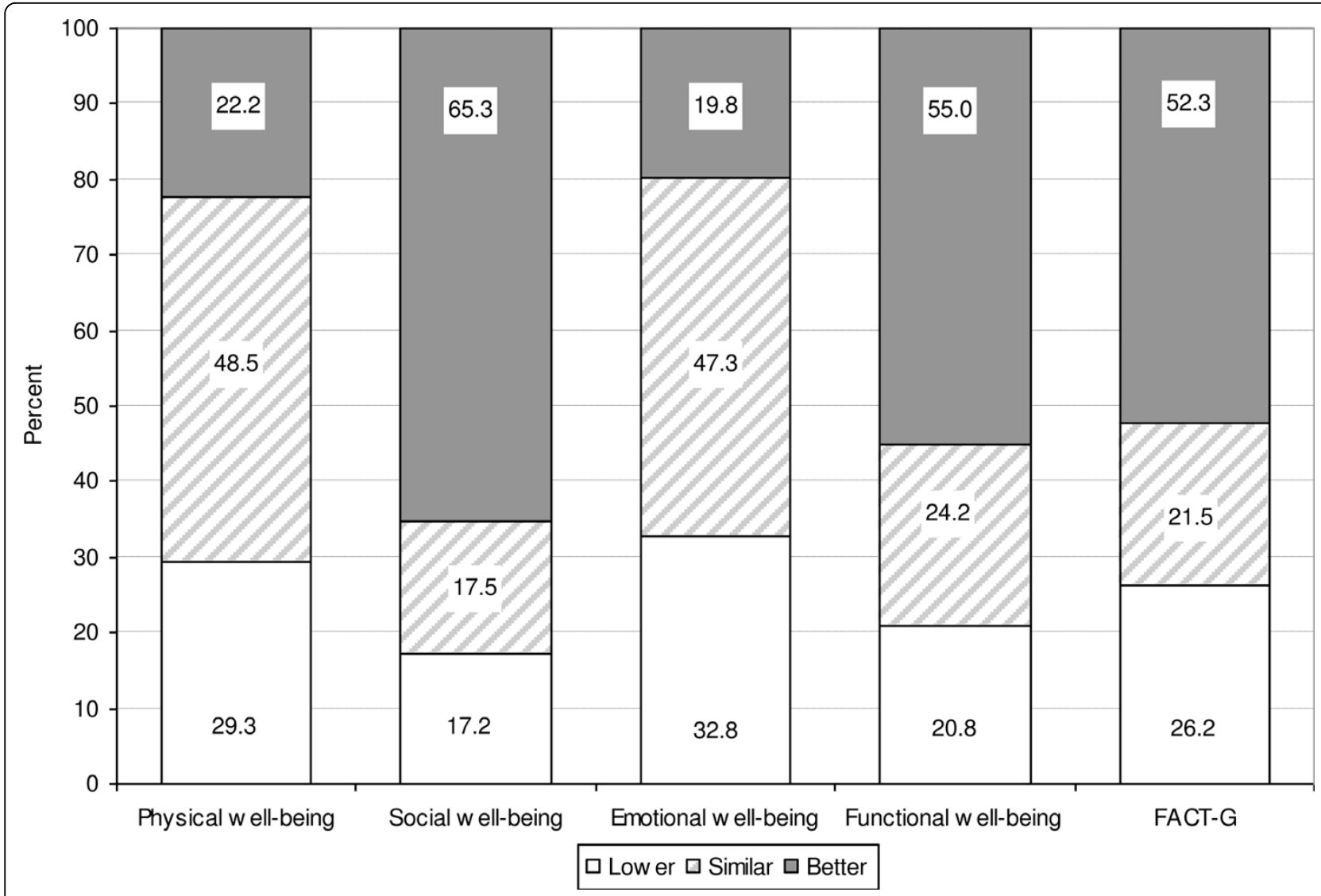

Figure 1 Proportions of breast cancer survivors whose relative QOL at 12 months post-diagnosis was lower than, similar to, or better than general population peers.

their non-urban counterparts 12 months following diagnosis, differences did not reach the threshold for clinical importance even for those subscales that were statistically significant (physical, emotional, and overall QOL, $P$ $<0.01$ ). In contrast, well-being related to breast cancer concerns was lower among non-urban compared to urban survivors by statistical $(P<0.01)$ and clinical criteria (Table 2). Furthermore, for both groups, women reported most detriment to their QOL for this subscale, with participants reporting mean values below $80 \%$ of the maximum score on average. Participants reported mean values at approximately $80 \%$ of the maximum score for all other subscales.

\section{Breast cancer survivors' QOL compared to the general population}

Table 3 presents the subscale and overall mean FACT-G scores for breast cancer survivors compared with women from the general population, stratified by residence and adjusted for potential confounding factors. At 12 months post-diagnosis, urban and non-urban breast cancer survivors reported clinically higher social wellbeing compared with their general population peers, and non-urban breast cancer survivors also reported clinically lower physical well-being $(P<0.01$ for all). Scores for emotional, functional and overall (FACT-G) QOL were clinically comparable to their counterparts from the general population despite a statistically significant difference for emotional and functional well-being $(P<$ 0.01 ).

Using the new outcome measure of QOL relative to age and residency-matched women from the general population, depending on the specific QOL scale, between $17.2 \%$ and $32.8 \%$ of all women with breast cancer reported clinically lower QOL 12 months following diagnosis than age- (within five years) and residencematched women without the disease. A further 17.5\%$48.5 \%$ of women reported similar QOL, while the remainder (19.8\%-65.3\%) reported clinically better QOL (Figure 1). The subscales with the highest proportions below the norm were emotional (32.8\%) and physical (29.3\%) well-being, and overall QOL (26.2\%).

\section{Characteristics associated with QOL below normative} levels among breast cancer survivors

Following adjustment for potential confounding factors, a range of characteristics were associated with breast 
Table 4 Correlates of QOL (FACT-G) below the norm at 12 months post-diagnosis among breast cancer survivors ${ }^{a}$

\begin{tabular}{|c|c|c|c|c|}
\hline \multirow[t]{2}{*}{ Characteristics } & \multicolumn{4}{|c|}{ Model } \\
\hline & $n$ & $\mathrm{OR}^{\mathrm{b}}$ & $95 \% \mathrm{Cl}$ & $P$-Value \\
\hline Place of residence & & & & 0.82 \\
\hline Urban & 277 & 1.00 & - & \\
\hline Non-urban & 323 & 1.06 & $0.64,1.74$ & \\
\hline Age (years) & & & & 0.21 \\
\hline$<50$ & 205 & 1.00 & - & \\
\hline $50+$ & 395 & 0.72 & $0.43,1.20$ & \\
\hline Occupation & & & & 0.38 \\
\hline Professional & 182 & 1.00 & - & \\
\hline White-collar worker & 176 & 1.16 & $0.64,2.11$ & \\
\hline Blue-collar worker & 31 & 2.53 & $0.95,6.76$ & \\
\hline Homemaker & 106 & 1.29 & $0.63,2.62$ & \\
\hline Retired/student & 105 & 0.92 & $0.43,1.96$ & \\
\hline Yearly income & & & & 0.15 \\
\hline$<\$ 52,000$ & 336 & 1.00 & - & \\
\hline$\$ 52,000+$ & 207 & 0.60 & $0.35,1.04$ & \\
\hline Missing & 57 & 0.66 & $0.28,1.55$ & \\
\hline $\begin{array}{l}\text { Private health insurance } \\
\text { status }\end{array}$ & & & & 0.05 \\
\hline No & 217 & 1.00 & - & \\
\hline Yes & 383 & 0.61 & $0.37,0.99$ & \\
\hline $\begin{array}{l}\text { Overall histological } \\
\text { grade }\end{array}$ & & & & 0.34 \\
\hline Grade 1 & 142 & 1.00 & - & \\
\hline Grade 2 & 219 & 0.58 & $0.32,1.06$ & \\
\hline Grade 3 & 208 & 0.69 & $0.38,1.24$ & \\
\hline Not available & 31 & 0.54 & $0.14,2.10$ & \\
\hline $\begin{array}{l}\text { Number of } \\
\text { complications }^{c}\end{array}$ & & & & $<0.01$ \\
\hline None & 187 & 1.00 & - & \\
\hline Yes, one to four & 413 & 2.26 & $1.31,3.90$ & \\
\hline Upper-body function & & & & $<0.01$ \\
\hline Good function $(<11)$ & 301 & 1.00 & - & \\
\hline Poor function $(11+)$ & 258 & 4.44 & $2.66,7.40$ & \\
\hline Missing & 41 & 3.63 & $1.45,9.07$ & \\
\hline Amount of stress & & & & $<0.01$ \\
\hline Very little/some & 371 & 1.00 & - & \\
\hline $\begin{array}{l}\text { A moderate amount/ } \\
\text { a lot }\end{array}$ & 229 & 4.77 & $2.93,7.76$ & \\
\hline $\begin{array}{l}\text { Perceived handling of } \\
\text { stress }\end{array}$ & & & & $<0.01$ \\
\hline Very well/fairly well & 526 & 1.00 & - & \\
\hline $\begin{array}{l}\text { Not well/not well at } \\
\text { all }\end{array}$ & 74 & 4.24 & $2.21,8.15$ & \\
\hline
\end{tabular}

Notes:

(a) Mutually adjusted for all variables in the model.

(b) Odds ratio for QOL below the norm $\left(R^{2}=0.43\right)$.

(c) Complications include wound infection, other infection, skin reaction, seroma. cancer survivors reporting overall (FACT-G) QOL below normative levels (Table 4), but place of residence (i.e., urban versus non-urban) was not one of these (Odds Ratio $(\mathrm{OR})=1.06$; 95\% Confidence interval $(\mathrm{CI})=0.64$ 1.74). Experiencing one or more complications following surgery was associated with two-fold increased odds $(\mathrm{OR}=2.26,95 \% \mathrm{CI}=1.31-3.90 ; P<0.01)$ of reporting reduced QOL, while upper-body function below the median, moderate or higher stress levels and poor perceived handling of stress were each associated with at least four-fold increased odds of reporting reduced QOL (ORs ranging from 4.24-4.77, $P<0.01$, see Table 4). A marker of higher socioeconomic status, having private health insurance, was associated with a 0.6 odds of reporting lower relative QOL $(95 \% \mathrm{CI}=0.37-0.99, P=$ $0.05)$.

\section{Discussion}

Urban and non-urban breast cancer survivors reported similar levels of QOL 12 months following diagnosis, overall and for subscales. The sole exception was the breast cancer concerns subscale, which showed that non-urban residents fared worse than their urban counterparts. When comparing breast cancer survivors to age- and residence-matched peers, the only detriment to QOL was among non-urban breast cancer survivors who reported statistically and clinically poorer physical well-being. Overall, up to one in three breast cancer survivors reported QOL below the age- and residencymatched general female population. The major independent correlates of reporting overall QOL below that of age-matched women without breast cancer were complications following surgery, poorer upper-body function, higher perceived stress levels, and poor perception of handling stress.

Despite the known differences by geographic residence with regards to access to services, availability of treatment and survival outcomes, our results indicate only minor disparities in QOL between urban and non-urban breast cancer survivors 12 months post-diagnosis. The subscale measuring breast cancer-specific concerns yielded the lowest values (based on percent of maximum score) reported by all survivors, but in particular for women living in non-urban areas. Items within this subscale deal with treatment-related symptoms, such as swelling of the arms, pain, shortness of breath, body image and sexuality. These results support existing research which demonstrates that while QOL among breast cancer survivors improves considerably during the first year following completion of treatment, breast 
cancer treatment-related concerns (such as arm dysfunction, poor body image, and sexual dysfunction) may persist [35-39].

It is plausible that non-urban survivors suffer in terms of their breast cancer-specific QOL, more so than urban survivors, as a consequence of inequalities in accessing specialised services. However, study-specific data collection procedures may also have contributed. QOL scores were derived from the third questionnaire for participants in the longitudinal urban breast cancer study, whereas the first (and only) questionnaire was the source of QOL data for non-urban breast cancer participants. Therefore urban survivors may have responded differently to QOL questions over time, not only because their QOL changed, but also because they may have become used to answering questions about QOL and might have over time changed their perception of QOL. This response shift may, in part, explain what appears to be a more positive breast cancer-specific QOL among urban survivors than non-urban survivors. However, the difference in QOL was observed on most but not all subscales, suggesting that response shift played a minor role in our findings.

On average, QOL was similar for breast cancer survivors and general population peers, for both urban and non-urban residents, similar to results reported by other authors studying QOL among breast cancer survivors 12 months $[40,41]$ or longer $[18,26,42]$ following diagnosis. The high FACT-G scores observed among breast cancer survivors are somewhat surprising, because patients frequently report ongoing symptoms and long-term sideeffects [35,36,39]. High functional and social well-being reported by breast cancer survivors compared to their general population counterparts contributed to their overall high FACT-G score and contradicts previous research $[18,26,40-42]$. However, the literature is dominated by studies using the European Organisation for the Research and Treatment of Cancer QOL questionnaire (EORTC QLQ-C30) $[18,26,40,41]$. The social wellbeing subscale of the EORTC QLQ-C30 and the FACT have been shown to be poorly correlated $(r=0.09)$ [43] suggesting they measure different aspects of social wellbeing. Furthermore, QOL domains measured by the FACT-G may be more relevant to short-term recovery. Whereas 12 months or longer after diagnosis, alternate issues may become more important for QOL, such as fear of recurrence or making meaning of the cancer experience. More recently, survivorship-specific QOL instruments have been developed, and further research is needed to assess whether these will uncover additional medium- to long-term survivorship issues [44].

Despite overall QOL similarities between survivors and their general population peers, up to one-third (depending on the subscale) of survivors continued to experience lower QOL 12 months following diagnosis of breast cancer. To our knowledge, despite Fayers suggesting advanced analytical procedures using normative scores in 2000 [34], this is the first study to assess correlates of lower QOL among breast cancer survivors in this manner. The results demonstrate that experiencing one or more treatment-related complications, reporting lower upper-body function than the median, moderate to high stress levels and/or perceived poor handling of stress could reduce the odds of good QOL two- to fourfold. The cross-sectional nature of the data denotes that these characteristics are correlates of QOL but not necessarily causes. Moreover, the relative QOL index used to identify these correlates may be focusing on those women with breast cancer who would have been in the lower part of the QOL range even before they had the disease. Regardless, these correlates have relevance for identifying subgroups of breast cancer survivors who require assistance to regain QOL to levels expected among age-matched peers from the general population.

Several key design features of this work highlight the strength and importance of the findings. Results were obtained from population-based urban and non-urban breast cancer samples, representative of their respective target populations [20-22], and therefore results are likely generalizable to the wider population of breast cancer survivors. Further, QOL of survivors were compared to peers without breast cancer, including matching for place of residence, allowing for more accurate interpretation of meaning of results. At a glance, the results from this study suggest that, overall, women with breast cancer fare well by 12 months following diagnosis; however, interventions are needed to improve breast cancer-related concerns among all women with breast cancer and physical well-being among non-urban survivors. These should specifically recruit those survivors who experience complications following surgery, upperbody dysfunction and/or those with a greater burden of stress (i.e., higher amounts and/or poor self-perceived handling of stress). Interventions that address such concerns and that are accessible for all women, irrespective of place of residence, may help facilitate a faster return to optimal QOL in the future.

\section{Conclusions}

Overall, the QOL of breast cancer survivors living in rural and urban areas was similar except for breast cancer related concerns being more dominant in women from rural locations. Among all women about 20\%-33\% have lower QOL one year past diagnosis compared to age matched women from the general population without breast cancer and thus could benefit from additional support and interventions. 


\section{List of abbreviations}

ARIA+: Accessibility/Remoteness Index of Australia; CI: Confidence Interval; EORTC: European Organisation for the Research and Treatment of Cancer; FACT: Functional Assessment of Cancer Therapy; FACT-G: Functional Assessment of Cancer Therapy-General; FACTGP: Functional Assessment of Cancer Therapy-General Population; FACTB+4: Functional Assessment of Cancer Therapy-Breast additional four questions; OR: Odds Ratio; PTS: Pulling Through Study; QOL: Quality of Life; QCRS: Queensland Cancer Risk Study.

\section{Acknowledgements}

This work was supported by the National Breast Cancer Foundation, with research project funding for the Pulling Through Study, scholarship support for the first author and fellowship support for the second author, and by the Cancer Council Queensland for the Queensland Cancer Risk Study. Monika Janda is supported by NHMRC-CDA-553034.

\section{Author details}

${ }^{1}$ School of Public Health, Institute of Health and Biomedical Innovation, Queensland University of Technology, Victoria Park Road, Kelvin Grove, Queensland, 4059, Australia. ${ }^{2}$ Viertel Centre for Research in Cancer Control, Cancer Council Queensland, PO Box 201, Spring Hill, Queensland, 4004, Australia.

\section{Authors' contributions}

TD carried out data collection and analysis. SH, BN, and MJ supervised TD and contributed to data interpretation and manuscript writing. JA supervised data collection at the Cancer Registry and provided critical input in data collection, analysis and manuscript. All authors read and approved the final manuscript.

\section{Competing interests}

The authors declare that they have no competing interests.

Received: 17 August 2009

Accepted: 7 January 2010 Published: 7 January 2010

\section{References}

1. American Cancer Society: Breast Cancer Facts Figures 2007-2008. Atlanta: American Cancer Society, Inc 2008.

2. Australian Institute of Health and Welfare (AlHW), Australasian Association of Cancer Registries (AACR): Cancer in Australia: An overview, 2006. Canberra: AlHW 2007.

3. Youlden D, Baade P, Coory M: Cancer Survival in Queensland, 2002. Brisbane: Queensland Health and Queensland Cancer Fund 2005.

4. Richardson L, Wang W, Hartzema A, Wagner S: The role of health-related quality of life in early discontinuation of chemotherapy for breast cancer. Breast J 2007, 13(6):581-587.

5. Coates A, Gebski V, Signorini D, Murray P, McNeil D, Byrne M, Forbes J, Australian New Zealand Breast Cancer Trials Group: Prognostic value of quality-of-life scores during chemotherapy for advanced breast cancer. J Clin Oncol 1992, 10(12):1833-1838.

6. Gupta D, Granick J, Grutsch J, Lis C: The prognostic association of healthrelated quality of life scores with survival in breast cancer. Support Care Cancer 2007, 15:387-393.

7. Mols F, Vingerhoets A, Coebergh J, Poll-Franse van de L: Quality of life among long-term breast cancer survivors: A systematic review. Eur J Cancer 2005, 41:2613-2619.

8. Hall S, Holman C, Hendrie D, Spilsbury K: Unequal access to breastconserving surgery in Western Australia 1982-2000. ANZ J Surg 2004, 74(6):413-419.

9. Kricker A, Haskill J, Armstrong B: Breast conservation, mastectomy and axillary surgery in New South Wales women in 1992 and 1995. Br J Cancer 2001, 85(5):668-673.
10. Thompson B, Baade $P$, Coory M, Carriere $P$, Fritschi $L$ : Patterns of surgical treatment for women diagnosed with early breast cancer in Queensland. Ann Surg Oncol 2008, 15(2):443-451.

11. Australian Institute of Health and Welfare (AlHW): Rural, Regional and Remote Health: Indicators of Health. Canberra: AlHW (Rural Health Series no. 5) 2005.

12. Clinical Oncological Society of Australia: Mapping Rural and Regional Oncology Services in Australia. COSA 2006.

13. NHMRC National Breast Cancer Centre: Clinical Practice Guidelines for the Management of Early Breast Cancer. Canberra: NHMRC, 22001.

14. Hegney D, Pearce S, Rogers-Clark C, Martin-McDonald K, Buikstra E: Close, but still too far. The experience of Australian people with cancer commuting from a regional to a capital city for radiotherapy treatment. Eur J Cancer Care 2005, 14(1):75-82.

15. Williams P, Rankin N, Redman S, Davis C, Armstrong B, Malycha P, Girgis A: National Survey of Women with Early Breast Cancer: Their Perceptions of Care (1997). Camperdown NSW: National Breast Cancer Centre 2004.

16. McGrath P, Patterson C, Yates P, Treloar S, Oldenburg B, Loos C: A study of postdiagnosis breast cancer concerns for women living in rural and remote Queensland. Part I: Personal concerns. Aust J Rural Health 1999, 7(1):34-42.

17. Lyons M, Shelton M: Psychosocial impact of cancer in low-income rural/ urban women: Phase II. Online Journal of Rural Nursing and Health Care 2004, 4(2).

18. Waldmann A, Pritzkuleit R, Raspe H, Katalinic A: The OVIS study: Health related quality of life measured by the EORTC QLQ-C30 and -BR23 in German female patients with breast cancer from Schleswig-Holstein. Qual Life Res 2007, 16(5):767-776.

19. Schultz A, Winstead-Fry P: Predictors of quality of life in rural patients with cancer. Cancer Nurs 2001, 24(1):12-19.

20. Hayes S, Janda M, Cornish B, Battistutta D, Newman B: Lymphedema after breast cancer: Incidence, risk factors, and effect on upper body function. J Clin Oncol 2008, 26(21):3536-3542

21. Round $T$, Hayes $S$, Newman B: How do recovery advice and behavioural characteristics influence upper-body function and quality of life among women 6 months after breast cancer diagnosis?. Support Care Cancer 2006, 14(1):22-29.

22. DiSipio T, Hayes S, Newman B, Janda M: What determines the healthrelated quality of life among regional and rural breast cancer survivors?. Aust N Z J Public Health 2009.

23. Commonwealth Department of Health and Aged Care: Measuring Remoteness: Accessibility/Remoteness Index of Australia (ARIA). Revised Edition. Occassional Papers: New Series Number 14. Canberra 2001.

24. DiSipio T, Rogers C, Newman B, Whiteman D, Eakin E, Fritschi L, Aitken J: The Queensland Cancer Risk Study: Behavioural risk factor results. Aust $N$ Z J Public Health 2006, 30(4):375-382.

25. Brucker P, Yost K, Cashy J, Webster K, Cella D: General population and cancer patient norms for the Functional Assessment of Cancer TherapyGeneral (FACT-G). Eval Health Prof 2005, 28(2):192-211.

26. Holzner B, Kemmler G, Cella D, De Paoli C, Meraner V, Kopp M, Greil R, Fleischhacker W, Sperner-Unterweger B: Normative data for functional assessment of cancer therapy: General scale and its use for the interpretation of quality of life scores in cancer survivors. Acta Oncol 2004, 43(2):153-160.

27. Cella D: Manual of the Functional Assessment of Chronic Illness Therapy (FACIT). Evanston: Center on Outcomes Research and Education (CORE), Evanston Northwestern Healthcare and Northwestern University 1997.

28. Cella D, Tulsky D, Gray G, Sarafian B, Linn E, Bonomi A, Silberman M, Yellen S, Winicour P, Brannon J, et al: The Functional Assessment of Cancer Therapy scale: Development and validation of the general measure. J Clin Oncol 1993, 11(3):570-579.

29. Australian Bureau of Statistics (ABS): Australian Standard Classification of Occupations. Canberra: ABS 1997.

30. Australian Taxation Office: Taxation Laws Amendment (Personal Income Tax Reduction) Bill 2003 (No. 163 of 2002-03). Canberra: Australian Government Publishing Service 2003.

31. Solway S, Beaton D, MCConnell S, Bombardier C: The DASH Outcome Measure User's Manual. Toronto: Institute for Work and Health, 2002.

32. Centers for Disease Control and Prevention (CDC): Behavioral risk factor surveillance system survey questionnaire. Atlanta, Georgia: US 
Department of Health and Human Services, Centers for Disease Control and Prevention 2001.

33. Australian Bureau of Statistics (ABS): 2001 Census of Population and Housing: Australia in Profile: A Regional Analysis. Canberra: ABS 2004.

34. Fayers P, Machin D: Quality of life: Assessment, analysis and interpretation. Chichester: Wiley \& Sons 2000.

35. Engel J, Kerr J, Schlesinger-Rabb A, Sauer H, Holzel D: Axilla surgery severely affects quality of life: Results of a 5 -year prospective study in breast cancer patients. Breast Cancer Res Treat 2003, 79(Supplement 1):4757.

36. Ganz P, Desmond K, Leedham B, Rowland J, Meyerowitz B, Belin T: Quality of life in long-term, disease-free survivors of breast cancer: A follow-up study. J Natl Cancer Inst 2002, 94(1):39-49.

37. Heim E, Valach L, Schaffner L: Coping and psychosocial adaptation: Longitudinal effects over time and stages in breast cancer. Psychosom Med 1997, 59(4):408-418.

38. King M, Kenny P, Shiell A, Hall J, Boyages J: Quality of life three months and one year after first treatment for early stage breast cancer: Influence of treatment and patient characteristics. Qual Life Res 2000, 9(7):789-800.

39. Shimozuma K, Ganz P, Petersen L, Hirji K: Quality of life in the first year after breast cancer surgery: Rehabilitation needs and patterns of recovery. Breast Cancer Res Treat 1999, 56(1):45-57.

40. Arndt V, Merx H, Sturmer T, Stegmaier C, Ziegler H, Brenner H: Age-specific detriments to quality of life among breast cancer patients one year after diagnosis. Eur $J$ Cancer 2004, 40(5):673-680.

41. Schou I, Ekeberg O, Sandvik L, Hjermstad M, Ruland C: Multiple predictors of health-related quality of life in early stage breast cancer. Data from a year follow-up study compared with the general population. Qual Life Res 2005, 14(8):1813-1823.

42. Ahn S, Park B, Noh D, Nam S, Lee E, Lee M, Kim S, Lee K, Park S, Yun Y: Health-related quality of life in disease-free survivors of breast cancer with the general population. Ann Oncol 2006, 18(1):173-182.

43. Holzner B, Bode R, Hahn E, Cella D, Kopp M, Sperner-Unterweger B, Kemmler G: Equating EORTC QLQ-C30 and FACT-G scores and its use in oncological research. Eur J Cancer 2006, 42(18):3169-3177.

44. Pearce N, Sanson-Fisher R, Campbell H: Measuring quality of life in cancer survivors: A methodological review of existing scales. Psychooncology 2008, 17(7):629-640.

45. Department of Health and Aged Care: National physical activity guidelines. Canberra: Commonwealth Department of Health and Aged Care 2005.

doi:10.1186/1477-7525-8-3

Cite this article as: DiSipio et al.: Does quality of life among breast cancer survivors one year after diagnosis differ depending on urban and non-urban residence? A comparative study. Health and Quality of Life Outcomes 2010 8:3.

\section{Publish with Bio Med Central and every scientist can read your work free of charge}

"BioMed Central will be the most significant development for disseminating the results of biomedical research in our lifetime. "

Sir Paul Nurse, Cancer Research UK

Your research papers will be:

- available free of charge to the entire biomedical community

- peer reviewed and published immediately upon acceptance

- cited in PubMed and archived on PubMed Central

- yours - you keep the copyright 